\title{
Preliminary observations on the development of dominance in partial-isolation-reared monkeys (Macaca irus)
}

\author{
RATHE KARRER and LINDA DEKKER \\ Illinois State Pediatric Institute \\ Intl) I'. Rocose'telt Rd. Chicago. Ill. 60608
}

Macaca irus, reared without physical contact with other monkeys for 6 of 12 months after birth, were deficient in dominance-submissiveness behaviors. A relatively short period of group experience at age 2.5 years resulted in the development of dominance-submissiveness behavior. Therefore, social experience later in development appears to be effective in reversing some of the consequences of early social deprivation.

Both partial and total isolation of primates early in life have been found to have profound and lasting effects on later social behavior (Clark. 1968; Cross \& Harlow, 1965: Mason. 1960: Mitchell, 1968, 1970). Deprivation has been observed to result in higher levels of fear and self-directed disturbance activity, such as stereotypic motor activity and nonnutritive sucking, as well as lower levels of sexual behavior and social exploration (Harlow \& Harlow, 1965; Mason, 1960, 1961a; Missakian, 1969). There is evidence that these behaviors may be long-lasting even in partial isolates (Suomi, Harlow, \& Kimball, 1971). In brief, isolate animals exhibit bizarre behavior patterns and often respond inappropriately or inadequately in social situations.

Dominance is one aspect of social interaction that reflects a system of priorities that enable a monkey group to live together. To this extent, dominance-submissiveness behavior is important to a monkey's social adjustment and survival. Mason (1961b) found that the dominance interactions of restricted rhesus monkeys were less frequent, and reflected a less stable hierarchy, than were those of a group of feral-born controls. According to Alexander and Harlow (1965), infants lacking early peer experiences are less dominant than those with peer experience. Contrarily, Angermeier \& Phelps (1967) found no difference in dominance of rhesus monkeys reared under four different conditions of enrichment and isolation from the age of 2 to 4 months. Sackett (1967), however, found a general rank-order relationship between amount of stimulation early in life and social behavior at 4 years of age. Inappropriate social responses and a high level of immature play patterns are apparently important factors in the inability of socially restricted rhesus monkeys to form normal relationships (Mitchell \& Clark, 1968). The inability of isolated animals to interpret and use facial communication skills (Miller. Caul, \& Mirsky, 1967) contributes to these factors. Brandt, Stevens, \& Mitchell (1971) have also shown abnormal visual and auditory communication in adult isolates.

It seems therefore. that the social skills necessary to maintain normal. stable dominance relationships are learned early in life. Clark (1968) concludes that social experience prior to the age of 3 or 4 months is necessary for the development of "adaptive positive social responses." However. such social experience was apparently insufficient to inhibit development of later abnormal aggressive behavior.

The reversibility of the effects of social isolation has received little study. Mitchell et al (1966) have reported some partial recovery of social behavior of total isolate rhesus. Essentially complete social recovery in isolate infants living for 6 months with younger female "therapist" infants has been reported by Harlow \& Suomi (1971). Brandt \& Mitchell (1973) have also reported some social therapeutic effects of normal female preadolescents on isolate infants. Adult group experience of 3 to 6 months has also reportedly (Missakian, 1972) effected positive change in two of three socially deprived monkeys. This change was reflected in increased social grooming and mounting behavior as well as decreased aggression. Reversibility of the effects of isolation must depend upon many factors, including the nature and duration of isolation, age at isolation and at therapy, the nature of the therapy and its duration, the sex of the isolate and therapist, as well as the targeted behavior for therapy. Any of these factors may vary with the species under study. The above studies have all utilized Macaca mullata (rhesus) monkeys.

The present paper contributes to the question of reversibility by presenting some observations on the dominance relationships of Macaca irus (reared partially isolated) before, during, and after a period of group living. These observations are reported because of their importance, even though they were collected during pilot observations in preparation for a larger study of early experience effects.

\section{METHOD}

Eight monkeys, which had been previously studied during their first year of development by Berkson (1968), were observed from about 18 to 36 months of age. The monkey's were lab-born within a 5 -month period and had been separated from their mothers at specific times, ranging from birth to 6 months after birth (see Table 1). After separation from the mother. they were housed individually until they were 1 year old. During this time they had no physical contact with other monkeys. and only limited visual contact. A complete account of their treatment during the first year has been given by Berkson (1968). Unfortunately. from 12 to 16 months of age, five animals had limited social interaction during reorganization of the laboratory. Monkey $\mathrm{F} 1$ shared the same transport cage with an unknown other monkey from a different lab. Monkeys F4 and $M 1$ were housed together for an unknown period. as were F6 and F7. At 16 months of age. these $S s$ were again housed individually with minimal visual interaction and no physical interaction. 
Table 1

Age (in Months) Removed from Mother. Age at Dominance Testing, and Weight at Last Paired Food Competition

\begin{tabular}{ccccccc}
\hline Monkey & $\begin{array}{c}\text { Age Removed } \\
\text { from Mother }\end{array}$ & $\begin{array}{c}\text { Age 1st } \\
\text { Pairing }\end{array}$ & $\begin{array}{c}\text { Age 2nd } \\
\text { Pairing }\end{array}$ & $\begin{array}{c}\text { Age at } \\
\text { Grouping }\end{array}$ & $\begin{array}{c}\text { Age } \\
\text { 3rd Pairing }\end{array}$ & $\begin{array}{c}\text { Weight (Kg) } \\
\text { 3rd Pairing }\end{array}$ \\
\hline M1 & Birth & 19.5 & 28.0 & 31.5 & 35.0 & 3.44 \\
F2 & 1 & 20.5 & 29.0 & 32.5 & 36.0 & 3.34 \\
F5 & 1 & 18.0 & 26.5 & 30.0 & 33.5 & 1.94 \\
F3 & 2 & 20.0 & 28.5 & 32.0 & 35.5 & 2.54 \\
F7 & 2 & 17.5 & 26.0 & 29.5 & 33.0 & 3.16 \\
F4 & 4 & 19.5 & 28.0 & 31.5 & 35.0 & 3.0 \\
F1 & 6 & 21.5 & 30.0 & 33.5 & 33.5 & 2.10 \\
F6 & 6 & 18.0 & 26.5 & 30.0 & 34.8 \\
Mean & & 19.3 & 27.8 & 31.3 & \\
\hline
\end{tabular}

Observations of initiation of physical aggression. gaping. threat vocalizations. and displacement of position were taken as expressions of dominance behavior. Grimacing, lip-tongue smacking. and withdrawal were taken as expressions of submissive behavior. A second measure of dominance-submissiveness behavior was obtained in a food competition task. Pairings for food competition were done using a different cage to which each animal alone had been previously adapted. After $24 \mathrm{~h}$ of food deprivation, each animal was paired once with every other animal. a total of 28 pairings. The same $S$ was never used in consecutive pairings. Pieces of apple were placed within reach of each pair. while two Os watching from behind a screen recorded general behavioral notes and which animal obtained the food. At least nine presentations of food were made to each pair. The animal of the pair obtaining the food on the greatest number of trials was considered to be dominant. The eight animals were then ranked according to the number of pairings in which they were dominant. If two animals were dominant in an equal number of pairings. they were given the same rank. Both series of pairings, therefore, produced two measures of rank. one from the food competition and another from general observations. Three series of pairings were done at about 19. 28. and 35 months of age (Table 1). It should be noted that all but the male (M1) evidenced the onset of puberty (perianal swelling and menstruation) by the second pairing at 28 months.

After the first two pairings at 19 and 28 months, all eight animals were moved to a group living cage. During 2 months of group living. they were closely observed on a daily basis for social activities. They were then tested in group food competition. This was done as follows: After $54 \mathrm{~h}$ of food deprivation. fruit was presented to the group in their home cage. About 16 small pieces of apple were placed on the wire mesh top of the cage. which allowed all the animals time to gather around and try to obtain some. Food was presented 32 times in one session while two Os recorded which animal obtained the food and any dominant-submissive behavior. Each $\mathrm{O}$ ranked the eight animals on the basis of food-getting in this test as well as on the basis of observations of dominant-submissive behavior.

Upon completion of this group test, the third series of 28 pairings for food was performed, using the method outlined above.

\section{RESULTS}

Dominant-submissive behaviors were not often observed in the first two food-competition tests (see Table 2). In the first pairing (age 19 months), only 4 of the 28 pairings showed clear dominant-submissive behavior accompanying the food-getting. All of these pairs involved the male (M1). Thus, except for M1, all animals were lacking in clear dominance-submissiveness behavior in the test. In the second pairing (age 28 months), only 10 of the 28 pairings exhibited clear dominant-submissive behavior. These involved either the male, M1, and/or Female F6, both of which had experienced limited social contact prior to the study.

Although these two food-competition tests gave the rankings in Table 2 and were highly correlated with each other (rho $=0.834 . p<.01)$. they did not correspond to the two Os' judgement of the presence of dominant-submissive behavior. There was a general lack of dominant-submissive behaviors (i.e.. physical aggression, displacement, grimacing, withdrawl, etc.). so that no judgment of ranks could be made. While obtaining food was by definition dominant behavior. this measure did not reflect the observed behavioral interactions. These interactions were minimal, and did not involve competitive activity by either animal. Protocols of typical behaviors observed were: first apple presented-"F7 and F3 came to front of cage. There was no interaction and no hurry. F7 [arrived] just before F3 and grabbed the apple. F3 looked at F7 face with blank expression and no interaction." Second apple-"F7 and F3 at front; both grabbed but F3 got apple. F7 looked [at] apple and F3 but no interaction occured and no expression of aggression, or submission by either." Sometimes one member of a pair would not attempt to get the apple and there were no behaviors indicating that the second member was overtly inhibitory.

Table 2

Dominance Ranks Before and After Group Living

\begin{tabular}{|c|c|c|c|c|c|}
\hline \multirow[b]{3}{*}{ Monkey } & \multicolumn{2}{|c|}{ Before } & \multicolumn{3}{|c|}{ After } \\
\hline & \multirow{2}{*}{$\begin{array}{c}\text { 1st Food } \\
\text { Pairing }\end{array}$} & \multirow{2}{*}{$\begin{array}{l}\text { 2nd Food } \\
\text { Pairing }\end{array}$} & \multicolumn{2}{|c|}{$\begin{array}{c}\text { Group } \\
\text { Food Test* }\end{array}$} & \multirow{2}{*}{$\begin{array}{c}\text { 3rd Food } \\
\text { Pairing }\end{array}$} \\
\hline & & & A & B & \\
\hline F3 & 4 & 5 & 1 & 1 & 1 \\
\hline F4 & 1 & 3 & 2 & 2 & 2 \\
\hline M1 & 2 & 1 & 4 & 4 & 3 \\
\hline F6 & 2 & 1 & 3 & 5 & 4 \\
\hline F7 & 3 & 2 & 5 & 3 & 5 \\
\hline F5 & 6 & 7 & 6 & 6 & 6 \\
\hline F2 & 2 & 4 & 7 & 8 & 6 \\
\hline $\mathrm{F} 1$ & 5 & 6 & 8 & 7 & 6 \\
\hline
\end{tabular}

${ }^{*} A=$ obserners' evaluation within group: $B=$ food getting rank within group. 
Cnlike the first two pairings. a great deal of dominant-submissive behavior was exhibited by the eight animals after I months of group living. Their social interactions then constituted a well-defined dominance hierarchy. Two rankings were obtained for the group food test. one based on food-getting and the other based on the Os' evaluation. As may be seen. they correspond well (rho $=0.881, p<.01$ ). It is of interest that two animals ( 11 and F4) that had lived a short while together prior to the study established a relationship in the group situation. This relationship was observed as: "M1 and F4 attack F6": "M1 and F4 threaten F2": "M1 and F4 with their mouths together": and "M1 and F4 huddle together."

The third pairing for food after the 2 months of group living reflected the same hierarchy as was present in the group (Table 2: rho $=0.917$ for $\mathrm{A}$ vs 3 rd: 0.870 for $\mathrm{B}$ vs 3rd; $p<.01)$. This time, 20 of the 28 pairs exhibited clear, vigorously competitive dominance relationships. A complete range of dominant-submissive behavior was displayed. with intense food competition. The hierarchy was different from that given by the first and second food pairings (rhos $=0.572,0.477$. not significant for 1 vs 3 and 2 vs 3 , respectively).

We did not find that dominance correlated with age, weight, or time of separation from the mother. Since there was only one male in the group. nothing can be determined about the relationship of sex and dominance.

\section{DISCUSSION}

Dominance behavior, aggression. and threatening are present in infant and preadolescent rhesus monkey's 8 to 10 months of age (Brandt \& Mitchell, 1973). Jensen. Bobbitt. \& Gordon (1971) demonstrated consistent dominance ranks in infant pigtail (Macaca nemestrina) monkey's and concluded that there was a basic pattern of dominant-submissive interaction in infants. While there is little known of the development of dominance behavior in Irus. it is reasonable to assume that dominance relations are also present in normal Irus between 18 and 30 months of age -the age at which our partial isolates lacked dominance behavior.

Since early social experience is important in the development of dominance behavior, the absence of well-defined dominant-submissive behavior in the first two pairings is not surprising. The two animals (M1 and F6) that did exhibit some dominance behavior in these pairings had shared a cage with another animal for a short time previous to the observations. That small amounts of social experience. after 1 year of isolation, may exert powerful effects was also demonstrated by the relationship established by F 4 and $\mathrm{Ml}$ in the group situation. This may have influenced their positions (two and three) in the hierarchy. Increase in dominance by familiar cagemates has been reported by Masserman. Wechkin. \& Woolf (1968), although their animals had considerably more familiarity experience.

The important result is that clear dominance-submissiveness behaviors did appear after 2 months of group living between the ages of 2.5 and 3 years. This relatively short time of group living stimulated the expression of competitive behavior that was not exhibited beforehand.

While our systematic observations stopped with the last food pairing at about 3 years. occasional follow-up observations indicated that the hierarchy remained stable until about 4 vears of age. At that time. the previous leader (I 3 ) was displaced to next to bottom. The male also became much more aggressive. althougl still not able to challenge $\mathrm{F}$ emale $\mathrm{F} 4$. who held top rank for the next year that we retained the group. Since we had stopped regular systematic observations. We do not know what other group factors contributed to the change. 1

As we had no control over our animals and conditions prior to our observations, the data are necessarily a preliminary attempt to investigate the reversal of the isolate monkey's inability to form normal cominance relationships. Nevertheless, social experience later in development appears to be effective in reversing some of the consequences of early social deprivation.

\section{REFERENCES}

Alexander, B. K., \& Harlow, H. F. Social behavior of juvenile rhesus monkeys subjected to different rearing conditions during the first six months of life. Zoologische Jahrbucher Psysiologie, 1965, 71, 498-508.

Angermier, W. F., \& Phelps, J. B. Dominance in monkeys: Behavior and biochemistry. Technical Reports, QRL-TR-6724, 6517st Aeromedical Research Lab., 1967.

Berkson, G. Development of abnormal stereotyped behaviors. Developmental Psychobiology, 1968.1.118-132.

Brandt, E. M., \& Mitchell, G. Pairing preadolescents with infants (Macaca mulatta). Developmental Psychology, 1973, 8. 222-228.

Brandt, E. M., Stevens, C. W., \& Mitchell, G. Visual social communication in adult male isolate-reared monkeys (Macaca mulatta). Primates, 1971, 12, 105-112.

Clark, D. L. Immediate and delayed effects of early, intermediate and late social isolation in the rhesus monkey. Unpublished doctoral dissertation, University of Wisconsin, 1968.

Cross, H. A., \& Harlow, H. F. Prolonged and progressive effects of partial isolation on the behavior of Macaque monkeys. Journal of Experimental Research on Personality, 1965, 1, $39-49$.

Harlow, H. F. \& Harlow, M. K. The affectional systems. In A. M. Schrier, H. F. Harlow, and F. Stollnitz (Eds.), Behavior of non-human primates. Vol. 2. New York: Academic Press, 1965

Harlow, H. F., \& Suomi, S. J. Social recovery by isolation-reared monkeys. Proceedings of the National Academy of Science, $1971,68,1534-1538$.

Jensen, G. D., Bobbitt, R. A., \& Gordon, B. N. Dominance testing of infant pigtailed monkeys reared in different laboratory environments. Proceedings of the 3rd International Congress of Primatology, 1970, 3, 92-99 (Basel: S. Karger, 1971.)

Mason, W. A. The effects of social restrictions on the behavior of rhesus monkeys: I. Free social behavior. Journal of Comparative \& Physiological Psychology, 1960, 53, 582-589.

Mason, W. A. The effects of social restrictions on the behavior of rhesus monkeys: II. Tests of gregariousness. Journal of Comparative \& Physiological Psychology, 1961 a, 54, 287-290.

Mason, W. A. The effects of social restrictions on the behavior of rhesus monkeys: III. Dominance tests. Journal of Comparative \& Physiological Psychology, 1961b, 54, 694-699.

Masserman, J. H. Wechkin, S., \& Woolf, $M$ Alliance and aggressions among rhesus monkeys. In Science and psychoanalysis. Vol. XII. New York: Grune \& Stratton, 1968.

Missakian, E. A. Reproduction behavior of socially deprived adult male rhesus monkeys (Macaca mulatta). Journal of Comparative \& Physiological Psychology, 1969, 69, 403-407.

Missakian, E. A. Effects of adult social experiences on patterns of reproductive activity of socially deprived male rhesus monkeys (Macaca mulatta). Journal of Personality \& Social Psychology, 1972, 21, 131-134.

Miller, R. E., Caul, W. F., \& Mirsky, I. A. Communication of affects between feral and socially isolated monkeys. Journal of Personality \& Social Psychology, 1967, 7, 231-239.

Mitchell, G. Persistent behavior pathology in rhesus monkeys following early social isolation. Folia Primatologica, 1968, 8 . 132-147.

Mitchell, G. Abnormal behavior in primates. In L. A. Rosenblum (Ed.), Primate behavior. New York: Academic Press, 1970.

Mitchell, G. D., \& Clark, D. L. Long term effects of social isolation in non-socially adapted rhesus monkeys. Journal of Genetic Psychology, 1968, 113, 117-128.

Mitchell, G. D., Raymond, E. J., Ruppenthal, G. C., \& Harlow, H. F. Long term effects of total social isolation upon behavior of rhesus monkeys. Psychological Reports, 1966 18, 567-580.

Sackett, G. P. Some persistent effects of different rearing conditions on preadult social behavior of monkeys. Journal of Comparative \& Physiological Psychology, 1967, 64, 363-365.

Suomi. S. J., Harlow, H. F.. \& Kimbell. S. D. Behavioral effects of prolonged partial social isolation in the rhesus monkey. Psychological Reports, 1971.29.1171-1177. 


\section{NOTE}

1. During the 2.5 years these animals were housed together until age 5, no successful copulation by the male was observed. His typical attempts were as follows: "M1 sits down behind F4 and tries to pull her to him; makes feeble thrusts and then begins masturbatory activity." Further, none of the females exhibited adequate sexual presenting. While not systematically studied, all three Os agreed that no apparent change in this social behavior had taken place.

(Received for publication June 29. 1973.) 